
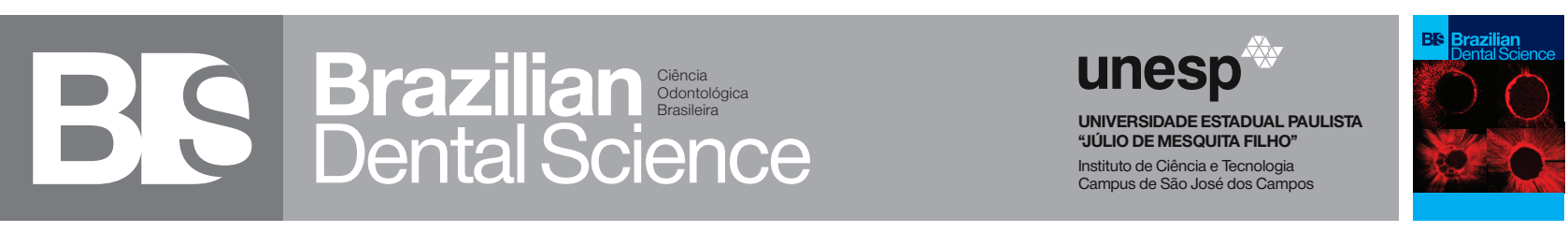

\title{
Study of the pterygoid canal (vidian canal) through images of cone beam computer tomography
}

Estudo do canal Pterigóideo (canal Vidiano) por meio de imagens de tomografia computadorizada de feixe cônico

Fernanda Fritoli Marcondes SANTANA ${ }^{1}$, Marcos Paulo Motta SILVEIRA ${ }^{2}$, Pedro Jacy Santos DIAMANTINO ${ }^{1}$, Karolina Aparecida Castilho FARDIM $^{2}$, Luiz Roberto Coutinho MANHÃES JÚNIOR ${ }^{3}$, André Luiz Ferreira COSTA ${ }^{3}$, Guilherme de Siqueira Ferreira Anzaloni SAAVEDRA ${ }^{1}$, Sérgio Lucio Pereira de Castro LOPES ${ }^{2}$

1 - São Paulo State University (Unesp) - Institute of Science and Technology, São José dos Campos - Department of Diagnosis and Surgery - São José Dos Campos - SP - Brazil.

2 - São Paulo State University (Unesp) - Institute of Science and Technology, São José dos Campos - Department of Dental Materials and Prosthodontics, Institute of Science and Technology - São José Dos Campos - SP - Brazil.

3 - Postgraduate Program in Dentistry - Cruzeiro do Sul University (UNICSUL) - São Paulo - SP - Brazil.

\section{ABSTRACT}

Objective: The aim of this study was to evaluate the pterygoid canal (PC) by Cone Beam Computed Tomography (CBCT), establishing its configuration and proximity with anatomical structures. Material and Methods: We evaluated 398 CBCT exams, all from a public University radiology clinic archive. Four parameters were evaluated: single or double PC, distance between PC and the inferior part of the sphenoid sinus (SS), ratio of PC and SS and the distance between the PC and the foramen rotundum. Results: It was observed that most of the PC of the sample presented simple morphology, the most frequent type of relationship between the PC and the SS on both sides was the close contact with the wall. Among the cases that there were some distances between the PC and the inferior wall of the SS, the mean of this distance did not exceed $3.20 \mathrm{~mm}$, being the left side $(3.03 \mathrm{~mm})$ slightly closer than the right $(3.20 \mathrm{~mm})$. Finally, the distances between the PC and the corresponding Foramen Rotundum are presented with mean values of $5.87 \mathrm{~mm}$ for the right side and $6.31 \mathrm{~mm}$ for the left side. Conclusion: CBCT examination is of paramount importance for PC identification; once in the studied sample, the mean values found evidence the close relation between the PC and the SS.

\section{KEYWORDS}

Cone beam computed tomography; Endonasal approach; Vidian canal.

\section{RESUMO}

Objetivo: O objetivo deste estudo foi avaliar o CP pela TCFC, estabelecendo sua configuração e proximidade com estruturas anatômicas. Material e Métodos: Foram avaliados 398 exames de TCFC, todos de um arquivo público da clínica de radiologia da Universidade. Foram avaliados quatro parâmetros: CP único ou duplo, distância entre PC e parte inferior do seio esfenoidal (SS), razão entre PC e SS e a distância entre o PC e o forame redondo. Resultados: Observou-se que a maioria dos CP da amostra apresentava morfologia simples, o tipo de relação mais frequente entre o $\mathrm{CP}$ e o SS de ambos os lados foi o contato próximo com a parede. Entre os casos em que houve algumas distâncias entre o CP e a parede inferior da ES, a média dessa distância não excedeu $3,20 \mathrm{~mm}$, sendo o lado esquerdo $(3,03 \mathrm{~mm})$ um pouco mais próximo do que o direito $(3,20 \mathrm{~mm})$. Finalmente, as distâncias entre o PC e o forame redondo correspondente são apresentadas com valores médios de 5,87 mm para o lado direito e $6,31 \mathrm{~mm}$ para o lado esquerdo. Conclusão: O exame TCFC é de suma importância para a identificação do CP; uma vez na amostra estudada, os valores médios encontrados evidenciam a estreita relação entre o CP e o SS.

\section{PALAVRAS-CHAVE}

Tomografia computadorizada de feixe cônico; Abordagem endonasal; Canal Vidiano. 


\section{INTRODUCTION}

T he pterygopalatine fossa is an interosseous space of great anatomofunctional, pathological and surgical importance. This is due to its location, anatomical relationships and vasculonervous content that favor the spread of tumor pathologies. In it are the maxillary artery and the maxillary nerve, in addition to the parasympathetic pterygopalatine ganglion, from which branches are distributed to the nasal and buccal cavities, paranasal sinuses and parts of the orbital and cranial regions, extending to the face [1].

The pterygoid foramen, originating from the homonymous canal (PC), which is also called vidian canal, allows the arrival of the nerve and pterygoid to the pterygopalatine fossa. Its location on the posterior wall of the fossa is an important reference to microsurgery and endoscopic surgery, through different access ways, such as transbuccal, transmaxillary and transnasal. In endonasal surgical access to the pterygopalatine foramen and canal, to the pterygopalatine branch neurectomies, the thin bony lamina of the palatine sphenoid process is completely removed, with complete exposure of the contents of this canal.

In addition, there is a possibility that the PC may be inserted into the corresponding sphenoid sinus (SS).

Some studies have also shown the proximity between this canal and the foramen rotundum in the sphenoid bone, which makes it even more important for surgical accesses to be correctly located in relation to these structures [2-4].

Cone-Beam Computed Tomography (CBCT) is an imaging method that enables you to obtain thickness cuts between 0.4 to $0.07 \mathrm{~mm}$ without overlapping structures and provides high definition of hard tissues of the body. This technique enables reliable measurements to be made on images, with distortions considered negligible. One of its advantages is also cited as a lower radiation dose when compared to fan beam tomography. Its use in dentistry, as well as in specialties such as otolaryngology, has grown significantly in recent decades $[5,6]$.

One study [1] have already been performed in order to determine the position of the PC by means of fan beam tomography, however, few studies have found in the literature studies that use CBCT exams for such.

Since voxel - the geometric unit that makes up the images - has isotropic conformation with its three equivalent dimensions - unlike those that make up the images of fan beam tomography - anisotropic so-called - bone definition and identification of the smaller anatomical structures in CBCT becomes superior. Thus, the purpose of this research, PC study and its characterization and relationship with some structures such as SS and foramen rotundum, becomes unprecedented and of great importance.

\section{MATERIAL AND METHODS}

\section{Sample characterization}

After approval by the Research Ethics Co mmittee, protocol CAEE number 67662417.6.0000.0077, all stages of the same were performed at a radiology clinic in a university.

A total of 556 CBCT exams were evaluated, by the non-inclusion criteria, 398 CBCT exams were selected, making up the final sample. All examinations belonged to a university radiology clinic archive of patients of both sexes and of varying ages, with sharpness and field of view that encompassed the middle third of the face. Were excluded from the sample exams that did not have the region of interest, that had movement artifacts or that had previous lesions or surgical signs that compromised the evaluation of the region corresponding to the sphenoid bone.

All examinations were performed on the i-CAT Next Generation CT scanner (Imaging Sciences International, Hatfield, PA, USA) in the same protocol (FOV $16 \times 8 \mathrm{~cm}$ and voxel 
$0.25 \mathrm{~mm}$ ), covering the face and sphenoid bone region, being indicated by different purposes, such as implant planning, study of teeth included, periodontal studies, etc.

The images were evaluated by 01 previously trained examiner using XORAN software (Xoran Technologies, Ann Arbor, MI, USA) in the MPR (multiplanar reconstruction) window on a 19 inch LCD monitor in a properly darkened environment.

All images were observed simultaneously in the axial and coronal sections of the region corresponding to the sphenoid bone and pterygopalatine fossa. The Figures 1 and 2 show the location of the pterygoid channel (PC) in the sphenoid bone and the CBCT sections on the MPR windows.
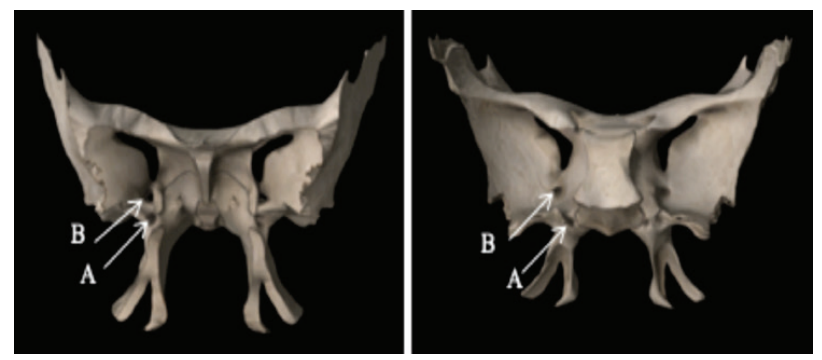

Figure 1 - Anterior (1) and posterior (2) views of the sphenoid bone, showing the Pterygoid (A) and Foramen Rotundum (B) canal (Source: 3D4 Medical, Dublin, Ireland).

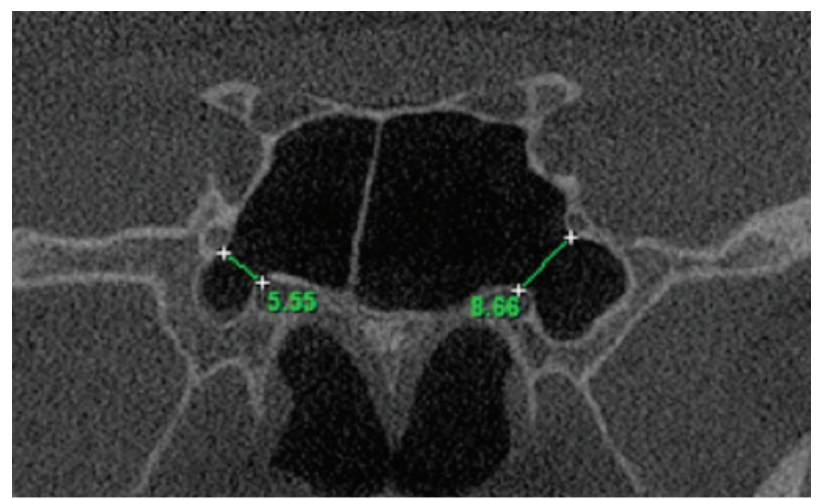

Figure 2 - MPR window of CBCT showing: pterygoid canal in the sphenoid bone $(A)$ and its relationship with: foramen rotundum (B), sphenoid sinus (C) and middle fossa of the skull (D) (Source: self-authored)
In CBCT images, some parameters on the Pterygoid Channel were evaluated with the following protocol:

\section{Single or Double}

Analyzed in the coronal throughout the body of the sphenoid bone. (Figure 3).
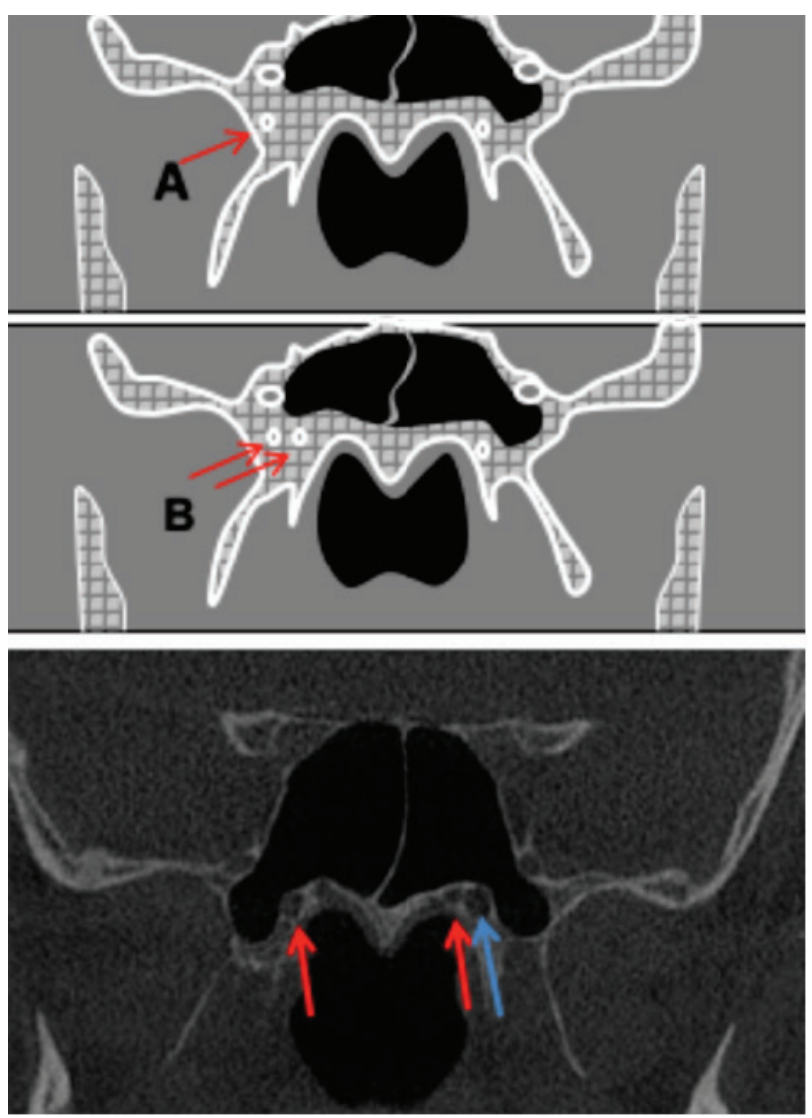

Figure 3 - Schematic of the sphenoid bone in a CBCT coronal section, exemplifying in $A$, single channel and $B$ double channel. Below coronal section of CBCT exemplifying on the right side single $\mathrm{CP}$ and on the left side double PC. (Source: self-authored) 
Distances between the canal and the corresponding inferior wall of the sphenoid sinus (SS)

It was analyzed in the coronal sections, in anterior to posterior scan, performed with the software distance tool, the measurement between the superior channel wall and the inferior wall of the SS, in three distinct sections: the most anterior, the middle and the posterior one. The distance of the smallest value is considered. (Figure 4).
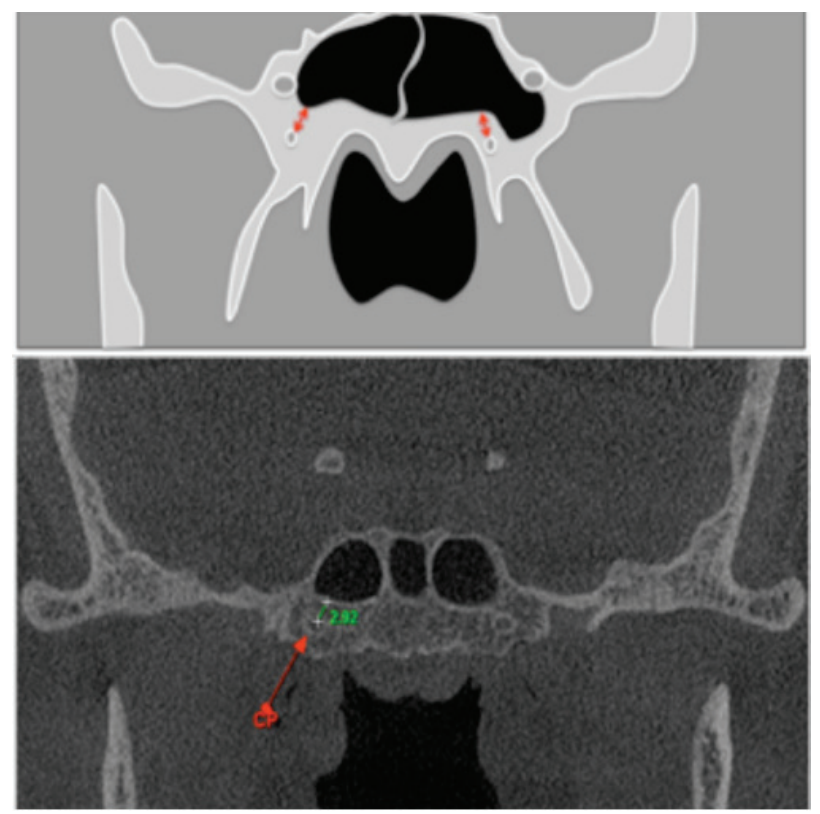

Figure 4 - $\mathrm{CBCT}$ coronal section showing the measurement between $\mathrm{PC}$ and sphenoid sinus. Below is a coronal section of CBCT showing the distance measurement between PC and SS. (Source: self-authored)

\section{Relationship with the corresponding sphenoid sinus (SS)}

The following relationships were considered: individualizing the sinus (type I), close contact with the wall (type II), protruding within the sinus (type III), and located within the sinus (type IV). They were analyzed in the coronal sections in all its extension and considered, if in the same canal there are variations, the one that is most related to the SS. (Figure 5).
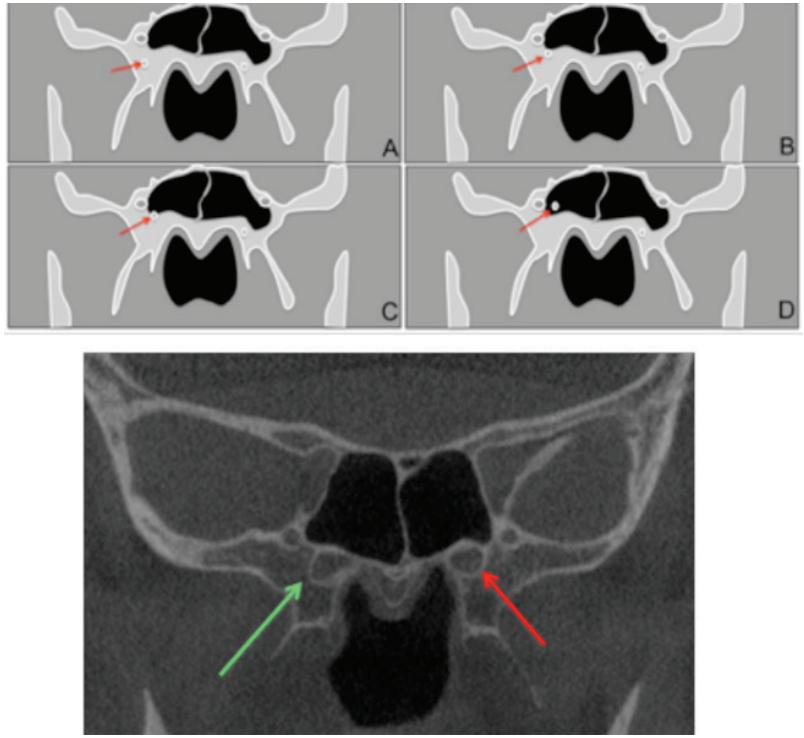

Figure $\mathbf{5}$ - CBCT coronal section showing the relationship between PC and SS: (A) individualized; (B) intimate contact; (C) protruded in the SS and (D) within the SS. Below, coronal view of CBCT showing: intimate counted PC and SS on the right side and protrusion of the PC on the left side. (Source: selfauthored)

\section{Distance between canal and foramen rotundum}

Distances between the PC and the foramen rotundum (FR) were measured with the line joining these two structures. (Figure 6).

All data were tabulated and submitted to descriptive statistical analysis.

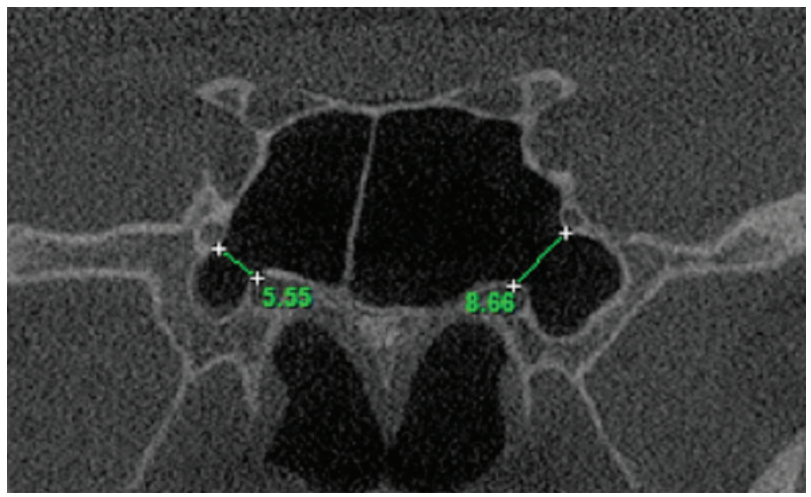

Figure 6 - Measurements of distances between the pterygoid canal (PC) and foramen rotundum (FR) (Source: self-authored). 


\section{RESULTS}

The sample consisted of 398 CBCT exams (796 CP), 164 males and 234 females. The mean age was 45.16 years.

Table I shows the frequency of PC types for morphology (single or double).

Table I - Frequency in the sample of PC types regarding their morphology. (Source: self-authored).

\begin{tabular}{|cccc|}
\hline Morfology & Right Side (\%) & Left Side (\%) & Total (\%) \\
\hline Single & $317(39.83)$ & $330(41.46)$ & $647(81.29)$ \\
\hline Double & $81(10.17)$ & $68(8.54)$ & $149(18.71)$ \\
\hline Total $(\%)$ & $398(50.00)$ & $398(50.00)$ & $796(100.00)$ \\
\hline
\end{tabular}

From Table I, it can be observed that most of the PC in the sample belonged to the simple morphology, for both sides (right and left) corresponding to $81.29 \%$ of the sample. Double PC had a frequency of less and $20 \%$ of the samples (18.71\%).

Regarding the types of relationship between the PC and the respective sphenoid sinuses (SE), Table II shows the frequencies found in the sample.

Table II - Frequency in the sample of the types of relationship between the PC and the corresponding sphenoid sinuses (SS) (Source: self-authored).

\begin{tabular}{|cccc|}
$\begin{array}{c}\text { Relationship } \\
\text { with SS }\end{array}$ & Right Side (\%) & Left Side(\%) & Total(\%) \\
I & $72(9.04)$ & $57(7.16)$ & $129(16.20)$ \\
II & $198(24.87)$ & $203(25.50)$ & $401(50.37)$ \\
III & $103(12.95)$ & $108(13.57)$ & $211(26.52)$ \\
IV & $25(3.14)$ & $30(3.77)$ & $55(6.91)$ \\
\hline Total & $398(50.00)$ & $398(50.00)$ & $796(100.00)$ \\
\hline
\end{tabular}

Table II shows that the most frequent type of relationship between the PC and the sphenoid sinuses, on both sides - right and left - was type II (50.7\%), corresponding to approximately half of the patients. evaluated channels, that is, the one in which the channels are in close contact with the SS walls. Sequentially, type III (26.52\%) (protruding in SS) and then type I (16.20\%) (individualized, or unrelated to SS), with a lower frequency on both sides, Type IV (within the SS) (6.91\%).

Regarding the distances between the PC and the inferior wall of the SS, Table III shows the results found in relation to the mean distances.

Table III - Mean distances between the PC and the inferior walls of the SS. (Source: self-authored)

\begin{tabular}{|cccc} 
& \multicolumn{3}{c}{ Distance } \\
& Mean $(\mathbf{m m})$ & Median $(\mathbf{m m})$ & Standard Deviation \\
\hline Right Side & 3.2 & 2.5 & 1.8 \\
\hline Left Side & 3.03 & 1.3 & 1.5
\end{tabular}

Table III shows that among the cases in which there was some distance between the PC and the inferior walls of the SS, the mean of this distance did not exceed $3.20 \mathrm{~mm}$, and the left side $(3.03 \mathrm{~mm})$, slightly more. close to the right $(3.20 \mathrm{~mm})$. Even the median value on the left side was lower than on the right (1. versus $2.5 \mathrm{~mm}$ ). The standard deviations were similar - 1.8 for the right side and 1.5 for the left side.

Table IV shows the values found in the sample concerning the distances between the $\mathrm{PC}$ and the corresponding foramen rotundum.

Table IV - Mean distances between the PC and the foramen rotundum (Source: self-authored).

\begin{tabular}{|cccc|} 
& \multicolumn{3}{c}{ Distance } \\
& Mean $(\mathbf{m m})$ & Median $(\mathbf{m m})$ & Standard Deviation \\
\hline Right Side & 5.87 & 5.41 & 1.1 \\
\hline Left Side & 6.31 & 5.78 & 2.89 \\
\hline
\end{tabular}

It can be seen from Table IV that the distances between the PC and the corresponding foramen rotundum are with mean values of 5.87 $\mathrm{mm}$ for the right side and $6.31 \mathrm{~mm}$ for the left side, and the median values very close for both. (5.41 $\mathrm{mm}$ to the right and $5.78 \mathrm{~mm}$ to the left), slightly greater distance prevailing on the left side, with standard deviation but greater on this side (2.89) compared to the right (1.10). may indicate that there were some value(s) that caused discrepancies in the results, leading to an increase in the median and mean value on the left side. 


\section{DISCUSSION}

The identification of the vidian canal on CT images is important considering the endoscopic sphenoid sinus surgery, the transnasal endoscopic approach of the internal carotid artery, the transnasal endoscopic surgery of the skull base or tumors resulting from the vidian nerve $[7,8]$. The vidian canal can be dissected and followed during endoscopic endonasal surgery to improve orientation and location of important anatomy $[9,10]$.

Some studies have shown the value of fan beam computed tomography (or multislice) in this function. However, this imaging modality presents a high dose of radiation to the patient, and its spatial resolution may be lower than that obtained by cone beam computed tomography (CBCT), since the latter presents with isotropic voxel, leading to uniformity of images, lower noise and greater ability to identify structures.

Although some studies $[6,11]$ have already used CBCT to anatomically characterize PC, they are quite restricted to a specific population and none had been conducted targeting a sample of the South American population, specifically, the Brazilian population. These studies still differ from ours, since they only observed the distances between the PC and SS, not worrying about their characterization regarding the morphology (single or double) and about the anatomical relationship as the SE (intimate relationship, protruded, individualized). or inside) as performed herein.

The high prevalence of close contact between PC and SS indicates the importance of their study and is in agreement with the study by Mohebbi et al. (2016). This finding may be a warning for endoscopic surgeries, as well as the high frequency of protruded PC in the SS.

In this research, it was observed that most of the vidian canals in the sample were simple, which differed from studies [2], who used a larger sample than this study (1265 exams) multislice tomography. This fact could be explained by the lower definition of voxel images in multislice computed tomography that may lead to a difference in this identification [12]. In our study, voxel edge values $(0.25 \mathrm{~mm})$, even if not used with the maximum resolutions that CBCT can provide, ie values below 0.10 $\mathrm{mm}$, provide a higher resolution than those normally used for skull examinations. in CBCT. Moreover, in that imaging modality, the anisotropic voxel favors the so-called partial volume effect on the image, which leads to greater noise in the image, which is minimized by the conformation of the isotropic multislice tomography voxel. This may have explained the difference between our findings and that study [8] and reinforced its usefulness for this purpose. Studies comparing CBCT and multislice tomography for the identification of PC using the same sample, eg dry skulls, should be designed for a more informed conclusion.

The relationship between the vidian canals and the foramen rotundum was studied before [5] and the findings of this study corroborate ours with respect to the mean of the distances found here. These authors, however, did not consider in their sample those cases in which the channels were double and thus a discrepancy of results could occur if double measurements were performed. In our sample, when double PC was present, the measurement was made up to the foramen rotundum of the equidistant point between the two PC, corresponding to an mean.

Overall, the finding of our research came against those of some previous studies, but differing from the analysis methodology. CBCT proved to be a valuable imaging modality for the study of PC, and had the advantage of providing a lower dose to patients when compared to fan beam tomography.

We believe that our findings regarding vidian canal measurements and conformation can be used as a reference and values to determine its location and position relative to certain preoperative landmarks. Our results can help in the proper treatment for surgical procedures around the vidian canal with a 
high success rate and minimal complications. Therefore, the results obtained in this study will contribute to the literature.

\section{CONCLUSION}

In the sample studied, the Pterigoyde canal (vidian canal) was mostly of simple morphology, and in close contact with the corresponding sphenoid sinus wall.

The mean values found suggest proximity between the vidian canals and the inferior walls of the sphenoid sinuses and foramen rotundum, so it is important the close relationship between the vidian canals and the maxillary sinuses in procedures of access due to proximity and relationship, and the CBCT exam is an important tool for this.

Número do processo FAPESP 2018/11997-0

\section{REFERENCES}

1. Yazar F, Cankal F, Haholu A, Kiliç C, Tekdemir I.CT evaluation of the vidian canal localization. Clin Anat. 2007;20(7):751-754. doi:10.1002/ca.20496.

2. Hamid 0, EI Fiky L, Hassan 0, Kotb A, El Fiky S. Anatomic variations of the sphenoid sinus and their impact on trans-sphenoid pituitary surgery. Skull Base. 2008;18(1):9-15. doi:10.1055/s-2007-992764.
3. Mohebbi A, Rajaeih S, Safdarian M, Omidian P. The sphenoid sinus, foramen rotundum and vidian canal: a radiological study of anatomical relationships. Braz J Otorhinolaryngol. 2017;83(4):381-7.

4. Rahmati A, Ghafari R, AnjomShoa M. Normal variations of sphenoid sinus and the adjacent structures detected in cone beam computed tomography. J Dent (Shiraz). 2016;17(1):32-7.

5. Yamasaki A, Sedaghat AR, Lin GC, Curry WT, Shih HA, Gray ST. a rare finding of schwannoma of the vidian canal: a case report. J Neurol Surg Rep. 2015;76(1):e48-e51. doi:10.1055/s-0034-1544112.

6. Bahşi I, Orhan M, Kervancıoğlu P, Yalçın ED. The anatomical and radiological evaluation of the Vidian canal on cone-beam computed tomography images. Eur Arch Otorhinolaryngol. 2019;276(5):1373-83. doi:10.1007/s00405-019-05335-6.

7. Yeğin Y, Çelik M, Altıntaş A, Şimşek BM, Olgun B, Kayhan FT. Vidian canal types and dehiscence of the bony roof of the canal: an anatomical study. Turk Arch Otorhinolaryngol. 2017;55(1):22-6. doi:10.5152/tao.2017.2038

8. Yeh IK, Wu IS. Computed tomography evaluation of the sphenoid sinus and the vidian canal. B-ENT. 2013;9(2):117-21.

9. Mason EC, Hudgins PA, Pradilla G, Oyesiku NM, Solares CA. Radiographic analysis of the vidian canal and its utility in petrous internal carotid artery localization. Oper Neurosurg (Hagerstown). 2018;15(5):577-83. doi:10.1093/ ons/opx305.

10. Castelnuovo P, Nicolai P, Turri-Zanoni M, Battaglia P, Bolzoni Villaret $A$, Gallo S, et al. Endoscopic endonasal nasopharyngectomy in selected cancers. Otolaryngol Head Neck Surg. 2013;149(3):424-30. doi:10.1177/0194599813493073.

11. Kurt MH, Bozkurt P, Bilecenoğlu B, Kolsuz ME, Orhan K. Morphometric analysis of vidian canal and its relations with surrounding anatomic structures by using cone beam computed tomography [published online ahead of print, 2019 Aug 26]. Folia Morphol (Warsz). doi:10.5603/ FM.a2019.0094.

12. Kamburoğlu K. Use of dentomaxillofacial cone beam computed tomography in dentistry. World J Radiol. 2015;7(6):128-30. doi:10.4329/wjr. v7.6.128. 